\title{
К ПРОБЛЕМЕ ВИДОИЗМЕНЕНИЯ СЕМАНТИКО- СИНТАКСИЧЕСКИХ СВЯЗЕЙ ПРИ ОБОСОБЛЕНИИ
}

The work deals with the problem of transformation in syntactic and semantic relations in the sentences with detached attributes. This transformation is conditioned by the selection of peculiar language means for the necessary communicative effect.

Проблема преобразования синтаксических связей при обособлении является малоисследованной. Между тем, само явление преобразования отношений в предложении в случае наличия обособленного элемента не вызывает сомнения, на это неоднократно указывали многие лингвисты. В частности, отмечается, что если обычное определение связано с определяемым атрибутивной связью, при которой отнесенность признака предмету констатируется вне связи с моментом речи, то в обособленном определении признак приписывается предмету говорящим в соотнесении его по времени с моментом высказывания, оценивается он при этом говорящим и в модальном плане. Таким образом, при обособлении происходит именно установление, приписывание, а не констатация признака, что свидетельствует о предикативном характере связи. Однако поскольку модально-временная оценка признака при обособлении зависима от главной предикации предложения, возникающая синтаксическая связь признается полупредикативной.

Полупредикативный синтаксический характер связи обособленного элемента с определяемым обусловлен необходимостью его смыслового выделения, придания большего веса сообщаемой им информации в общей семантической структуре высказывания. Поэтому вряд ли можно согласиться с утверждением, что «...обособленный отрезок ... несет в себе оттенок дополнительного сообщения» [Грамматика 1970: 643; а также Валгина 2003: 229; Гак 2004:728]. Такой отрезок, напротив, как правило, становится главным смысловым компонентом, носителем ремы высказывания. Проведенное нами изучение большого количества постпозитивных и препозитивных обособленных определений подтверждает эту мысль.

Полученные данные свидетельствуют о том, что семантика и способ выражения обособленного определения тесно взаимосвязаны с семантикой и способом выражения сказуемого предложения, поэтому лишь ограниченный круг языковых элементов может оказаться в обособлении, причем для этого необходимы особые семантико-синтаксические условия. Наиболее красноречиво это подтверждается при исследовании предложений с обособленными прилагательными, поскольку в этом случае 
ярко выступает различие между констатируемым атрибутивным признаком (в случае необособленного определения-прилагательного) и приписываемым полупредикативным признаком (при обособлении определения-прилагательного).

Собранный материал выявляет существенное преобладание в обособлении прилагательных, передающих временное, а не постоянное качество, например: «She opened the door, and met Maria ... who, breathless with agitation, cried out...” [Austen 2006:119]. Важно отметить, что временный признак, выраженный в обособленном определении, отражает новизну данной информации, ее особую существенность в описываемой ситуации. Не менее знаменательным оказывается и характер определяемых обособленными прилагательными слов, среди которых преимущественно встречаются конкретные одушевленные существительные или местоимения, например: «Не backed away, stiff-legged with selfconsciousness, and tried to go around her" [London 2007: 126].

Таким образом, обособляемые элементы в подавляющем большинстве случаев являются носителями яркой призначной семантики, и определяемые ими конкретные лица описываются живо и соответственно с данным положением дел. Именно обособленные определения несут основную смысловую ситуативную нагрузку, в то время как сказуемые в обсуждаемых предложениях лишь передают физическое движение, что, как правило, менее существенно для характеристики ситуации. Приведем еще несколько примеров: «But at the front and rear, unawed and indomitable, toiled the two men who were not yet dead” [London 2007:4]; “After a few days, sober and bankrupt, Grey Beaver departed up the Porcupine...” London 2007:162].

Отметим, что обособляемые прилагательные с зависимыми словами, не только повышают свой синтаксический статус по сравнению с обычными определениями, но и усиливают способность к синкретическому выражению сопутствующих обстоятельственных значений, прежде всего значения причинности. Это свойство обособленных элементов можно наблюдать почти во всех вышеприведенных примерах, как и в следующем предложении: «Mr Collins, awkward and solemn, ...gave her all the shame...” [Austen 2006:68]. Предикативность и обстоятельственность обособленного определения может быть легко доказана с помощью трансформации, эксплицирующей эти семантико-синтаксические свойства: Mr Collins, as he was awkward and solemn, gave her all the shame. Как видим, трансформация выявляет скрытую предикативность прилагательных, причем характеристики, приписываемые персонажу в данной ситуации, являются причиной положения дел, описываемого главной предикативной линией с помощью подлежащего и сказуемого, и, следовательно, играют важную коммуникативную роль. 
Подводя итоги, подчеркнем, что именно обособленное определение принимает на себя функцию выделения наиболее релевантного в описываемой ситуации признака, что значительно повышает его статус в семантической и синтаксической структуре высказывания по сравнению с обычным определением, приближая его к статусу главных членов. Такое видоизменение семантико-синтаксических связей обусловлено выбором определенных языковых средств. В данной работе это было показано на примере предложений с обособленными прилагательными, однако ограниченность и избирательность языковых средств в случаях обособления была подтверждена и при исследовании обособления причастий, предложных оборотов, сравнительных конструкций. Выбираемые средства призваны обеспечить выражение новой и коммуникативно-существенной информации, зачастую более важной, нежели передаваемой в главной предикативной линии. Таким образом, обособление выступает как эффективный и экономный метод передачи комплекса взаимосвязанных смыслов.

\section{Литература:}

1. Валгина Н.С. Современный русский язык: Синтаксис. - М., 2003.

2. Гак В.Г. Теоретическая грамматика французского языка - М., 2004.

3. Грамматика современного русского литературного языка - М., 1970.

4. Austen J. Pride and Prejudice. - M., 2006.

5. London J. White Fang. - Новосибирск, 2007. 